\title{
The Diabetes 2-Month Turnaround
}

Reviewed by Renza Scibilia

Renza Scibilia is the author of the Diabetogenic blog (https://diabetogenic. wordpress.com) and is based in Melbourne, Australia.

Corresponding author: Renza Scibilia, rscibilia@diabetesaustralia.com.au

https://doi.org/10.2337/cd17-0108

(C)2017 by the American Diabetes Association. Readers may use this article as long as the work is properly cited, the use is educational and not for profit, and the work is not altered. See http:/I creativecommons.org/licenses/by-nc-nd/3.0 for details.

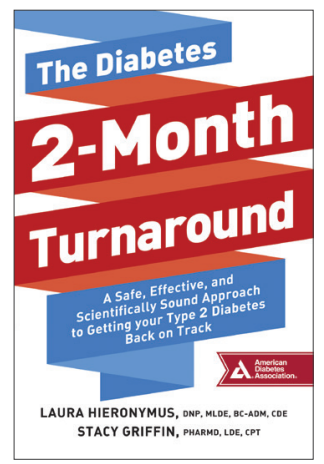

The Diabetes 2-Month Turnaround

BY LAURA HIERONYMUS AND STACY GRIFFIN

Publisher: American Diabetes Association

Publication date: 11 April 2017

Cost: $\$ 16.95$
A ny book or treatment promising quick improvement to diabetes management could be looked upon skeptically. Diabetes is complex, and a quick-and-easy approach is rarely feasible.

But what if there were a simple, efficient, and easy guide that did offer a solution in a relatively short time frame?

In The Diabetes 2-Month Turnaround, recently published by the American Diabetes Association, diabetes experts Drs. Laura Hieronymus (a nurse) and Stacy Griffin (a pharmacist) offer an 8-week program that promises a "safe, effective, and scientifically sound approach" to helping people with diabetes get their management back on track.

Each of the 8 weeks in their program focuses on seven key areas of diabetes as identified by the American Association of Diabetes Educators in its evidence-based framework of diabetes self-care. These areas include healthy eating, being active, monitoring, taking medication, problem-solving, reducing risks, and healthy coping.

All areas are given equal importance, and each week, different issues are covered within each area. For example, the problem-solving section covers topics such as managing hyperglycemia and hypoglycemia, managing sick days, and getting structured diabetes self-management and education.

The component on reducing risks addresses diabetes-related complications in a nonthreatening manner by providing clear definitions of and steps for minimizing each complication. There are also crucial sections on the importance of immunizations and vaccinations and why prepregnancy planning and care are important for women with diabetes who are planning for a baby.

Each week's healthy coping section looks at self-care behavior changes required to make consequential and sustainable improvements. 
However, the focus on behavior change is not reserved for these paragraphs alone. The overall approach throughout The Diabetes 2-Month Turnaround is for readers to set goals they can achieve and build on for all aspects of their diabetes management and overall well-being.

Perhaps the most useful takehome messages from the book are the practical tips the authors have sprinkled throughout. From an explanation of how to read food labels, to advice about how to make the most of health care appointments, patients will find useful and useable suggestions for easily incorporating healthy activities into their life.

This guide book is equally relevant to people newly diagnosed with type 2 diabetes and those who have been living with diabetes for a number of years and are looking for a refresher or new approach to how they manage the disease. Although the book is officially aimed at people living with type
2 diabetes, much of the advice-such as practical tips for increasing physical activity, evaluating healthy eating behaviors, travelling, and monitoring glucose-is also applicable to and useful for people living with type 1 diabetes.

\section{Duality of Interest}

No potential conflicts of interest relevant to this article were reported. 